\title{
Studies of the Mechanics of Pulmonary Ventilation in Patients with Bronchial Asthma
}

\author{
By \\ Tamotsu Takishima \\ (滝 島 任) \\ From Prof. T. Nakamura's Medical Clinic, \\ Tohoku University, Sendai
}

(Received for publication, July 23, 1956)

The chief complaint of asthmatic patient is dyspnea, but how this symptom occurs remains still considerably unknown. ${ }^{1-5)}$ Despite the accumulation of informations about pulmonary functions of asthmatic patients, many investigators $\left.\left.{ }^{1,4}, 4,6\right), 7,8\right)$ have chiefly concerned the problems of lung volume, pulmonary gas distributions, ventilations and recently pulmonary circulations. Moreover, these investigators have took account only for studies in remissions or after administration of the drugs as adrenalin.

According to peculiarity of this disease, the physiological investigation of dyspnea in asthmatic patient during paroxysm may include possible importance concerning to the genesis of bronchial asthma. Although this sort of study should need certainly measurements of the pressureflow relationship of the lung, ${ }^{9-25)}$ many have only attempted to obtain intrapleural pressure or flow rate at the mouth separately except Sheldon and $\mathrm{Otis}^{31}$ who reported intraalveolar pressure-resistance of bronchial canalization-flow rate relationships in remissions and after administration of epinephrine.

In previous study the present author observed evidently the diminution of vital capacity and one second vital capacity (or Tiffeneau's Index ${ }^{7)}$ ) of patients with bronchiectasis after inhalation of pilocarpin. Similarly in asthmatic patients spirograms change apparently 30-40 seconds after 1:100 pilocarpin inhalation, and characteristic asthma-like attacks are usually induced. The present study represents an attempt to explore functionally the behavior of the pulmonary tissues and bronchial trees during such asthma-like attack induced by pilocarpin inhalation.

\section{EXPERIMENTAL}

Experimental Procedure

8 patients with bronchial asthma clinically diagnosed and 5 normal 
individuals have been studied. Table I demonstrates lung volumes, RV/TLC $\times 100$, MBC, Tiffeneau's Indexes (one second vital capacity/vital capacity $\times 100$ ) and anatomical dead spaces capable to indicate pulmonary gas distribution of these patients.

TABLE I

Results of Ventilatory Functions in 8 Asthmatic Patients

\begin{tabular}{|c|c|c|c|c|c|c|c|c|c|c|}
\hline \multicolumn{3}{|c|}{ Subject } & \multicolumn{2}{|c|}{ Clinical diagnosis } & $\begin{array}{l}\text { TCL } \\
\text { (L) }\end{array}$ & $\begin{array}{l}\mathrm{VC} \\
\text { (L) }\end{array}$ & $\frac{0}{2} 8$ & $\begin{array}{c}\mathrm{MBC} \\
(\mathrm{L} / \\
\min .)\end{array}$ & 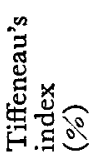 & 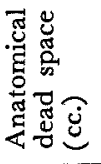 \\
\hline F.C. & oิ & 23 & \multicolumn{2}{|c|}{ Bronchial asthma } & 5.60 & 4.03 & 28.0 & 106 & 65.5 & 178 \\
\hline Y.M. & $\hat{o}$ & 37 & \multicolumn{2}{|c|}{$\begin{array}{l}\text { Bronchial asthma with } \\
\text { pulm. emphy. }\end{array}$} & 4.98 & 2.04 & 59.0 & 31 & \multirow[t]{2}{*}{$\begin{array}{l}33.0 \\
77.4\end{array}$} & 329 \\
\hline I.O. & oิ & 31 & \multicolumn{2}{|c|}{ Bronchial asthma } & 4.93 & 3.44 & 30.2 & 92 & & - \\
\hline K.M. & 今 & 48 & $"$ & $"$ & 7.71 & 4.49 & 41.7 & 86 & 58.5 & 190 \\
\hline I.S. & $\hat{o}$ & 54 & $"$ & $"$ & 6.25 & 4.09 & 34.5 & 79 & 62.0 & 240 \\
\hline Y.T. & o & 31 & $"$ & $"$ & 5.42 & 3.83 & 29.3 & 85 & 63.3 & 149 \\
\hline F.K. & 우 & 28 & $"$ & $"$ & 4.47 & 2.90 & 35.1 & 33 & 45.0 & 166 \\
\hline S.S. & ? & 60 & $\begin{array}{r}\text { Bronch } \\
\text { puln }\end{array}$ & $\begin{array}{l}\text { sthma with } \\
\text { phy. }\end{array}$ & 3.69 & 1.49 & 59.6 & 18 & 61.0 & 180 \\
\hline
\end{tabular}

Volume changes were measured by Krogh's respirometer with the potentiometer which was connected to the galvanometer electrically. The speed of air flow was recorded at the mouth with a Fleisch's pneumotachograph connected to the differential manometer (Druckdifferentialkapsel). As a measurement of transpulmonary pressure the pressure difference between the mouth and the lower portion of the oesophagus was recorded. The intraoesophageal pressure was transmitted to one side of a differential manometer which was made identically to Fleisch's Druckdifferentialkapsel by means of air-filled polyethylene tube $60 \mathrm{~cm}$. in length, $1.77 \mathrm{~mm}$. in inside diameter, with about 50 holes in the catheter wall at the distal end. ${ }^{15), 17), 22)}$ A thin-walled condome rubber balloon with a volume of $8 \mathrm{ml}$. undistended and $15 \mathrm{~cm}$. in length was sealed to the catheter and enclosed the openings. The other side of the manometer membrane was connected to the mouthpiece chamber by pressure tubing. The air volume of the balloon during recording was $1 \mathrm{ml}$. In front of the mouthpiece and the pressure tubing a solenoid valve was attached for instantaneous electrical interruption of respiratory flow. Volume changes, flow rates and pressures were recorded simultaneously on a three elements oscillograph.

All patients were studied asymptomatic remissions. Preliminary the determination of the volume and timed vital capacity was carried out 
utilizing the Knipping's and Krogh's respirometer in sitting position. Then the oesophageal balloon was swallowed. In some patients asthmatic attacks were provocated only by passing of the balloon through the nose so that the tracing of oscillogram was usually obtained 10 or more minutes after setting of the balloon into the oesophagus. Calculation was made from the data during resting and rapid breathing. After these procedures patients inhaled orally $1: 100$ solution of pilocarpin by nebulizer for 3060 seconds. Immediately after patients had complained breathlessness slightly as observing the pressure fluctuation of the oscillograph, the inhalation was stopped and in established paroxyms oscillograms were obtained. The last recording was taken after inhalation of $1: 1000$ adrenalin in the same way untill subjective symptom disappeared.

Calculation. The effective compliance of the lung ${ }^{2+)}\left(\mathrm{L} / \mathrm{cmH}_{2} \mathrm{O}\right)$ in this paper represents the relationship of lung volume change to the coresponding elastic pressure change at the instance of zero air flow of resting breathing and therefore it is usually smaller than the static compliance all of which does not effective even in normal subjects. The work used for elastic property of the lung ( $\mathrm{gm} . \mathrm{L} / \mathrm{L}$ ) is stored in the lung as potential energy inspiratorily, releasing it at expiration. The inherent limitation of the present experiment makes it impossible to obtain any absolute value of intraoesophageal pressure, so that the elastic work was calculated from volume change-intraoesophgeal pressure diagram assuming oesophageal pressure equals zero at the beginning of inspiration, and consequently trapezoid was reduced to a triangle in diagram. This assumption would seem to be sufficient for comparison. ${ }^{23)}$ The effective resistance $(\mathrm{cm}$.$\mathrm{H}_{2} \mathrm{O} / \mathrm{L} / \mathrm{sec}$.) is the relationship of the flow-resistive component of pressure difference between the mouth and the surface of the lung to the simultaneous rate of volume change of the lung, and equivalent to "viscance" of Bayliss \& Robertson. ${ }^{10)}$ The maximal value of effective resistance in a single breathing cycle is the maximal resistance. The non-elastic werk (gm. L/L) is required for flow-resistive properties of the lung and airways. All works were corrected to the work per liter ventilation for comparison.

\section{Results with Discussion}

\section{Normal subjects}

Results in normal subjects during quiet breathing are summarized in Table II. The effective compliances of normal lungs in 5 subjects were $0.157 \mathrm{~L} / \mathrm{cm} \cdot \mathrm{H}_{2} \mathrm{O}$ on an average which seemed to be lower compared with that of previous observors. The maximal resistances were 2.1 and $2.8 \mathrm{~cm}$. $/ \mathrm{L} / \mathrm{sec}$. in inspiration and expiration, respectively. The power factor was 0.47 resulting from $61^{\circ}$ in mean phase angle. The mechanical properties of the lungs in 5 normal subjects may best be seen by referring 
TABLE II

Mechnical Properties of the Lungs in 5 Normal Subjects

\begin{tabular}{c|c|c|c|c|c|c|c|c}
\hline Subject & $\begin{array}{c}\text { Effective } \\
\text { compliance } \\
\left(\mathrm{L} / \mathrm{cmH}_{2} \mathrm{O}\right)\end{array}$ & $\begin{array}{c}\text { Elastic } \\
\text { work } \\
(\mathrm{gm} . \mathrm{L} / \mathrm{L})\end{array}$ & $\begin{array}{c}\text { Maximal } \\
\text { resistance } \\
\left(\mathrm{cmH}_{2} \mathrm{O} / \mathrm{L} / \mathrm{sec}\right)\end{array}$ & \multicolumn{2}{|c|}{$\begin{array}{c}\text { Non-elastic } \\
\text { work } \\
\text { (gm.L/L) }\end{array}$} & $\begin{array}{c}\text { Phase } \\
\text { angle } \\
\left({ }^{\circ}\right)\end{array}$ & $\begin{array}{c}\text { Power } \\
\text { factor } \\
\text { (Cos } \theta)\end{array}$ \\
\cline { 1 - 8 } S.O. & 0.148 & 3.4 & 2.6 & 3.2 & 0.7 & 0.5 & 56 & 0.56 \\
N.S. & 0.115 & 4.3 & 1.4 & 1.0 & 0.8 & 0.4 & 63 & 0.45 \\
T.M. & 0.234 & 2.1 & 2.1 & 2.2 & 0.4 & 0.3 & 58 & 0.53 \\
K.S. & 0.128 & 3.9 & 2.6 & 4.1 & 1.0 & 0.7 & 64 & 0.44 \\
A.A. & 0.160 & 3.1 & 1.7 & 3.7 & 0.5 & 0.6 & 68 & 0.37 \\
\hline Mean & 0.157 & 3.3 & 2.1 & 2.8 & 0.7 & 0.5 & 61 & 0.47
\end{tabular}

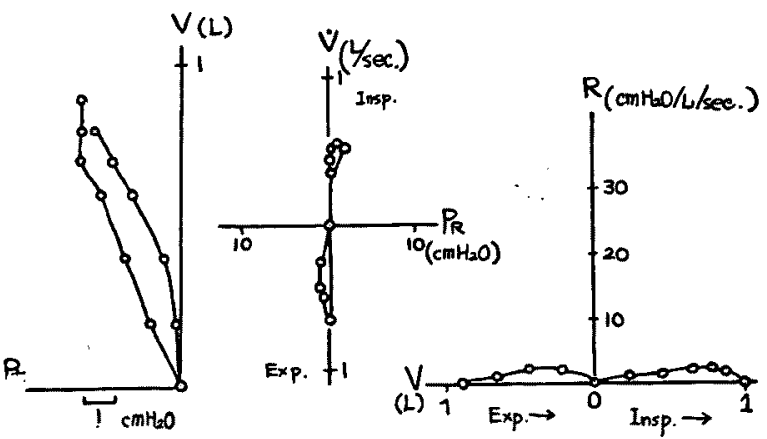

Fig. 1. Pressure-volume, pressure-flow rate and volume-resistance diagrams in normal subject. $V$ : volume change, $P_{t}$ : intraoesophgeal pressure, $\mathrm{V}$ : flow rate, $\mathrm{P}_{\mathrm{R}}$ : pulmonary pressure, $\mathrm{R}$ : resistance.

to diagrams in Fig. 1. In relationship of flow to pressure both inspiratory and expiratory curves described small loops in our experiments. The elastic energy stored in the lung inspiratorily was 0.33 gram $\mathrm{L} / \mathrm{L}$ and seemed to be enough to perform the expiratory non-elastic work not using any other energy than potential energy stored in it.

Asthmatic patients between attacks

Table III represents datas of breathing mechanics in asthmatic patients during remissions. The effective complicance was reduced slightly, resulting in the increase of elastic work. The maximal resistance in quiet breathing cycle increased markedly and the non-elastic work was approximately 4-fold of that in normal subjects. But no consistent difference was found in inspiratory and expiratory effective resistance. The moderate increment of the power factor due to the diminution of phase angle was also observed. 
TABLE III

Mechanical Properties of the Lungs in 8 Asthmatic Patients during Remissions

\begin{tabular}{l|c|c|c|c|c|c|c|c}
\hline Name & $\begin{array}{c}\text { Effective } \\
\text { compliance } \\
\left(\mathrm{L} / \mathrm{cm} . \mathrm{H}_{2} \mathrm{O}\right)\end{array}$ & $\begin{array}{c}\text { Elastic } \\
\text { work } \\
\text { (gm.L/L) }\end{array}$ & \multicolumn{2}{|c|}{$\begin{array}{c}\text { Maximal } \\
\text { resistance } \\
\left(\mathrm{cmH}_{2} \mathrm{O} / \mathrm{L} / \mathrm{sec} .\right)\end{array}$} & \multicolumn{2}{|c|}{$\begin{array}{c}\text { Non-elastic } \\
\text { work } \\
(\mathrm{gm} . \mathrm{L} / \mathrm{L})\end{array}$} & $\begin{array}{c}\text { Phase } \\
\text { angle } \\
(\mathrm{O})\end{array}$ & $\begin{array}{c}\text { Power } \\
\text { factor } \\
\text { (Cos } \theta)\end{array}$ \\
\hline F.C. & 0.11 & 4.6 & 8.1 & 10.2 & 6.3 & 4.8 & 8 & 0.99 \\
Y.M. & 0.20 & 2.5 & 6.6 & 6.4 & 3.6 & 2.8 & 9 & 0.98 \\
I.O. & 0.10 & 5.0 & 3.4 & 4.3 & 1.2 & 1.1 & 52 & 0.61 \\
K.M. & 0.13 & 3.9 & 1.3 & 2.8 & 1.0 & 1.7 & 81 & 0.15 \\
I.S. & 0.11 & 4.6 & 2.2 & 5.0 & 0.8 & 1.2 & 52 & 0.61 \\
Y.T. & 0.06 & 8.3 & 8.7 & 12.2 & 1.7 & 2.0 & 36 & 0.80 \\
F.K. & 0.11 & 4.6 & 10.5 & 13.5 & 2.4 & 1.7 & 9 & 0.98 \\
S.S. & 0.04 & 12.5 & 11.0 & 15.5 & 3.6 & 2.5 & 24 & 0.91 \\
\hline Mean & 0.11 & 5.7 & 6.4 & 8.7 & 2.5 & 2.2 & 33 & 0.75
\end{tabular}

These results indicate generally that asthmatic patients consume more energy for breathing than normal subjects even during remissions.

Asthmatic patients during attack

After 30-40 seconds of nebulization with 1:100 pilocarpin solution to asthmatic patients, asthma-like attacks were immediately and clearly provocated in nearly all cases. The tracing of the mouth-to-oesophagus pressure difference, rate of flow and volume change during voluntary ventilation are shown in Fig. 2. An upper tracing of a normal subject

Normal Subj.

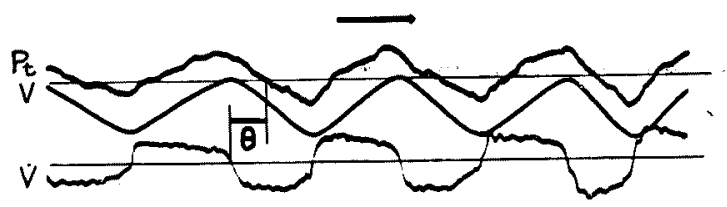

Asthmatic Pat.

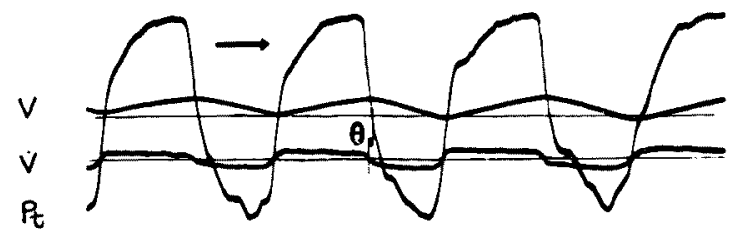

Fig. 2. Oscillograms during resting breathing in a normal subject and a asthmatic patient during attack. $\theta$ : phase angle. 
is shown for comparison with the lower of an asthmatic patient during attack. Breathing patterns are strikingly different. Although asthmatic patient reduced his tidal volume as well as flow rate, the marked fluctuation of pressure curve in a single breathing cycle was characteristic. The obliteration of irregularities in the flow patterns seems to be due to the increase of resistance without any calculation of resistance. If we may consider that the pulmonary system is analogous to an electrical circuit consisting of a capacitor and a resistor connected in series, the current with high frequency will pass in this system more freely than the low frequency current. Accordingly, many irregularities appear in flow rate of such recordings as in normal subjects. On the other hand, in asthmatic patients the resistor is enough increased to neglect the effect of a capacitor so that the irregularities of flow patterns will disappear. There were no prolonged expirations in asthmatic patients.

Immediately after administration of nebulized pilocarpin, Vital Capacity and Tiffeneau's Index were extensively reduced except one who had complained no dyspnea, as seen in Fig. 3. These diminution recovered mostly after adrenalin inhalation. The effective compliance of the lung decreased considerably, especially in a patient with pulmonary emphysema (Fig. 4). According to the decrease of compliance, the elastic

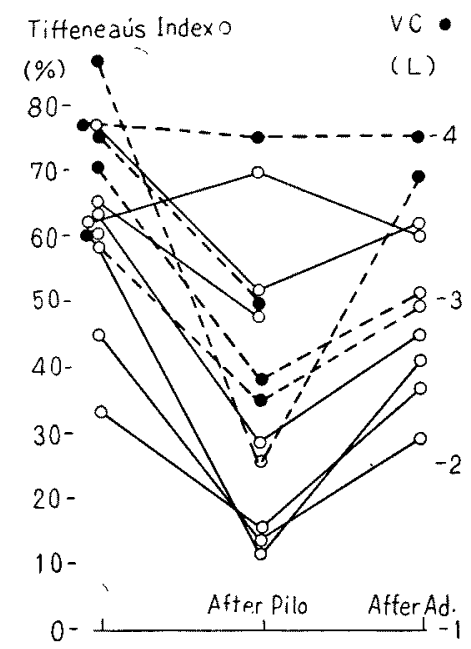

Fig. 3. Changes of Tiffeneau's index and vital capacity after pilocarpin and adrenalin inhalation.

work of the lung increased, in other words the lung became difficult to inflate. The striking increase in resistance of the lung and bronchial trees was also observed, resulting in greater work for frictional resistance 
both inspiratorily and expiratorily. Any important differences of resistance between inspiration and expiration were not found, similarly in remissions.

These relationships are graphically shown more clearly in following diagrams in which transpulmonary or flow resistive pressure difference is on the abscissa and volume change or flow rate on the ordinate. Initially, pressure-volume curves represent the marked change in the shape of the loop which shows pronounced flatness in asthmatic attack (Fig. 5).

Fig. 4

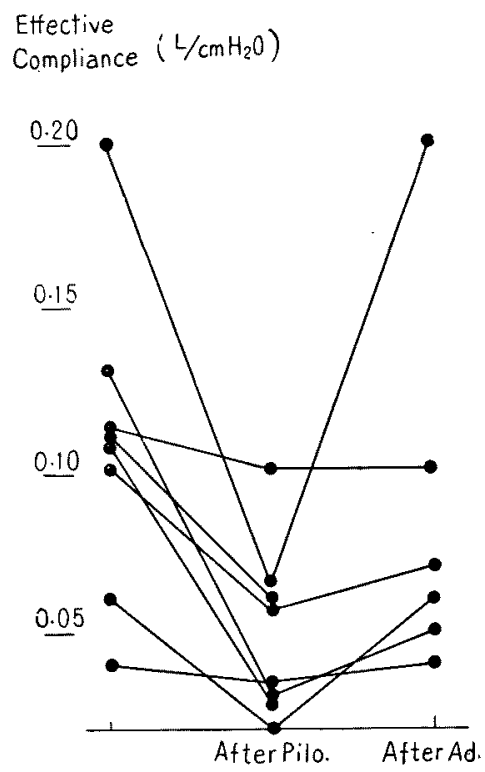

Fig. 5

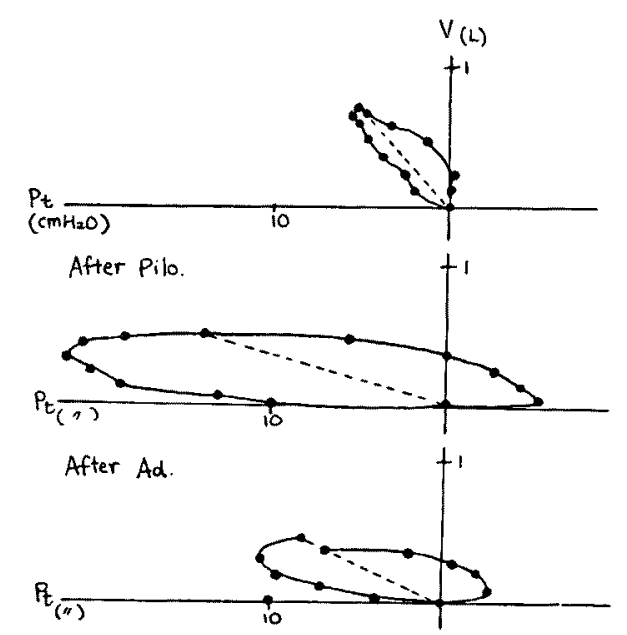

Fig. 4. Changes of the effective compliance after pilocarpin and adrenalin inhalation.

Fig. 5. Changes in pressure-volume graph of a asthmatic patient after pilocarpin and adrenalin inhalation.

This is undoubtedly due to the increase of resistance and may best be seen in pressure-flow graph (Fig. 6). These curves are not single lines but describe loops in both inspiration and expiration, although the latter recording little more large loops. The differences in volume-resistance graph between normal subjects and asthmatic patients are demonstrated in Fig. 7 with typical 3 cases. In remissions Patient K.M. showed normal resistance, which was increased strikingly after inhalation of pilocarpin, but adrenalin could not diminish the increased resistance to pre-pilocarpin value. In Pat. Y. M. with relatively high resistance in remissions the resistance recovered roughly to previous level after administration of adrenalin. Exceptionally, the increment of resistance did not appear 


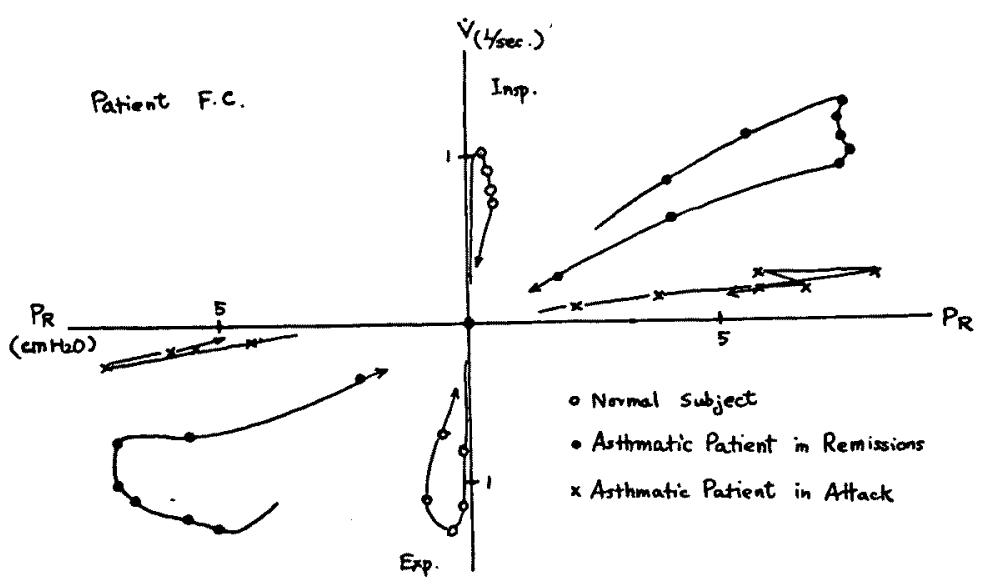

Fig. 6. Changes in pressure-flow diagram of a asthmatic patient after pilocarpin inhalation.

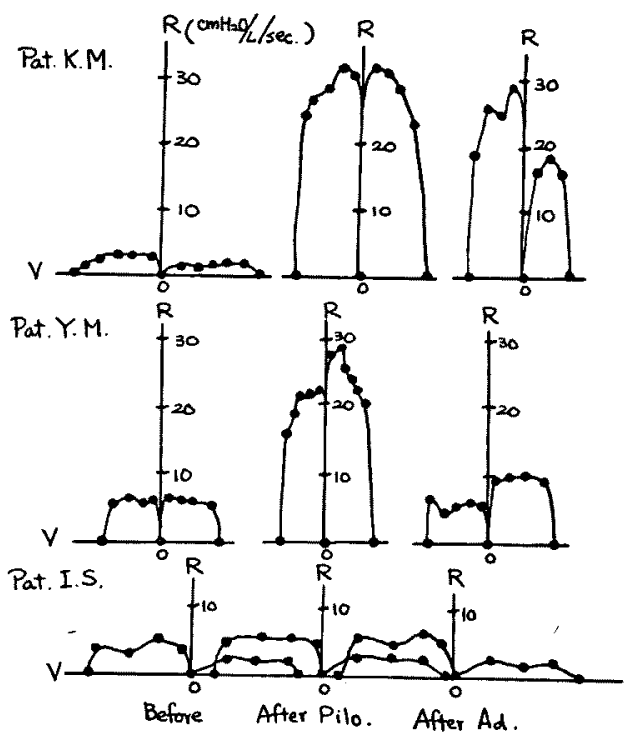

Fig. 7. Changes in volume-resistance diagrams of 3 typical cases with bronchial asthma after pilocarpin and adrenalin inhalation.

in one patient without attack by pilocarpin nebulization, as seen in Pat. I. S.

Even though 3 patients with moderate dyspnea in attack were associated with the marked pressure fluctuation in a single breathing cycle, the check valve mechanism which was reported by Dayman in his patients 
with pulmonary emphysema was not observed at the beginning of expiration. Table IV shows a summary of results in mean for all phases of patients. The work for elastic resistance was $13.1 \mathrm{gm} . / \mathrm{L}$ and the nonelastic work in expiration was $7.1 \mathrm{gm} . \mathrm{L} / \mathrm{L}$. Therefore, the ratio of these two works (elastic work/non-elastic work) is distinctly decreased relative to that in normal subjects.

\section{TABLE IV}

Mechanical Properties of the Lungs in Normal Subjects and in Asthmatic Patients during Remissions and after Pilocarpin or Adrenalin Inhalation

\begin{tabular}{|c|c|c|c|c|c|c|c|c|c|c|c|}
\hline \multirow[t]{2}{*}{ Subject } & \multirow{2}{*}{\multicolumn{2}{|c|}{ Phase }} & \multirow{2}{*}{ 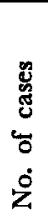 } & \multirow{2}{*}{ 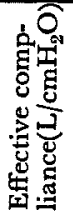 } & \multirow{2}{*}{ 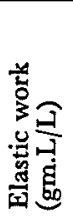 } & \multicolumn{2}{|c|}{$\begin{array}{c}\text { Maximal } \\
\text { resistance } \\
\left(\mathrm{cmH}_{2} \mathrm{O} / \mathrm{L}\right. \\
/ \mathrm{sec} .)\end{array}$} & \multicolumn{2}{|c|}{ 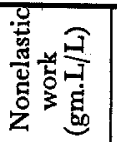 } & \multirow{2}{*}{ 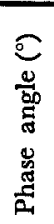 } & \multirow{2}{*}{ 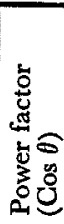 } \\
\hline & & & & & & 育 & $\dot{\overrightarrow{\dot{x}}}$ & 㤐 & 案 & & \\
\hline Normal & & & 5 & 0.16 & 3.3 & 2.1 & 2.8 & 0.7 & 0.5 & 61 & 0.97 \\
\hline \multirow{4}{*}{$\begin{array}{l}\text { Asthmatic } \\
\text { patients }\end{array}$} & \multicolumn{2}{|l|}{ Before } & 8 & 0.11 & 5.7 & 6.4 & 8.7 & 2.5 & 2.2 & 33 & 0.75 \\
\hline & \multirow{2}{*}{$\begin{array}{l}\text { After } \\
\text { pilocarpin } \\
\text { inhalation }\end{array}$} & All cases & 8 & 0.05 & 13.1 & 30.8 & 38.6 & 7.5 & 7.1 & 14 & 0.92 \\
\hline & & $\begin{array}{l}\text { Dyspnea (H) } \\
\text { cases }\end{array}$ & 3 & 0.03 & 19.5 & & $>67.6$ & 11.3 & 11.4 & 5 & 0.99 \\
\hline & \multicolumn{2}{|c|}{ After adrenalin inhalation } & 6 & 0.09 & 7.5 & 10.9 & 12.6 & 4.1 & 3.4 & 27 & 0.85 \\
\hline
\end{tabular}

Following to the opinion of Otis, ${ }^{23)}$ one would expect that the value of the ventilation maximally effective in lowering $\mathrm{P}_{\mathrm{E}} \mathrm{CO}_{2}$ would be lower than in the normal individual and in severe paroxyms $\mathrm{P}_{\mathrm{E} \mathrm{CO}_{2}}$ would be elevated conversely by breathing. The power factor was nearly 1 so that all energy disappears in this system by changing to heat. Assuming intraoesophageal pressure equals $-5 \mathrm{~cm} \mathrm{H}_{2} \mathrm{O}$ at resting expiratory level, ${ }^{11}$ it was imagined that 3 patients who complained dyspnea moderately needed certain works of expiratory muscles in expiratory movement of lungs in addition to the potential energy stored in the lung by its elastic properties.

Table $\mathrm{V}$ illustrates the relationship of objective dyspnea to the work for breathing at attack, especially representing close correlation of dyspnea to the total non-elastic resistance and the pressure fluctuation in a single breathing cycle. The elastic work is considerably related to objective dyspnea except a patient S. S. with the high elastic work already prior to inhalation of pilocarpin. The fact that dyspnea appears moderately when the total non-elastic work exceeds about $20 \mathrm{gm} . \mathrm{L} / \mathrm{L}$ and fluctuation of intraoesophageal pressure becomes more than $27-30 \mathrm{~cm} \mathrm{H}_{2} \mathrm{O}$ in a single 
TABLE V

Dyspnea and Work for Breathing

\begin{tabular}{|c|c|c|c|c|c|c|c|c|c|}
\hline & \multirow{2}{*}{ 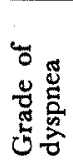 } & \multirow{2}{*}{ 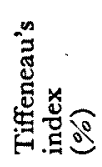 } & \multirow{2}{*}{ 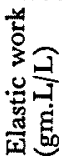 } & \multicolumn{2}{|c|}{$\begin{array}{l}\text { Maximal resistance } \\
\left(\mathrm{cmH}_{2} \mathrm{O} / \mathrm{L} / \mathrm{sec} .\right)\end{array}$} & \multicolumn{2}{|c|}{$\begin{array}{c}\text { Non-elastic } \\
\text { work } \\
\text { (gm.L/L) }\end{array}$} & \multirow{2}{*}{ 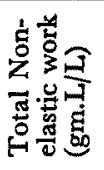 } & \multirow{2}{*}{$\begin{array}{l}\text { Fluctua- } \\
\text { ation of } \\
\text { intraoeso- } \\
\text { phageal } \\
\text { pressure } \\
\left(\mathrm{cmH}_{2} \mathrm{O}\right)\end{array}$} \\
\hline & & & & Insp. & Exp. & Insp. & Exp. & & \\
\hline Y.T. & H & 28.6 & 25.0 & 77.0 & 102.0 & 13.6 & 14.5 & 28.1 & 34 \\
\hline F.K. & H & 13.8 & 16.7 & $>33$ & $>69$ & 8.1 & 10.6 & 18.7 & 28 \\
\hline K.M. & H & 12.1 & 16.7 & 31.0 & 31.7 & 12.2 & 9.0 & 21.2 & 27 \\
\hline F.C. & + & 47.8 & 8.3 & 41.0 & 37.5 & 6.0 & 6.1 & 12.1 & 18 \\
\hline Y.M. & + & 15.5 & 8.3 & 29.5 & 24.5 & 8.1 & 5.8 & 13.9 & 17 \\
\hline I.O. & \pm & 51.5 & 8.3 & 11.6 & 14.2 & 5.6 & 4.4 & 10.0 & 15 \\
\hline S.S. & \pm & - & 16.7 & 21.0 & 24.3 & 4.9 & 4.2 & 9.1 & 14 \\
\hline I.S. & - & 69.9 & 5.0 & 2.5 & 5.6 & 1.5 & 2.9 & 4.4 & 11 \\
\hline
\end{tabular}

breathing cycle would seem to confirm the following hypothesis concerning to the genesis of dyspnea, i.e. dyspnea is brought about by stimulating some presso-receptor located in the thorax. ${ }^{2)} \quad$ Christie $^{12)}$ also reported the close relationship between dyspnea and the work for breathing in cardiac patients.

The dyspnea of asthmatic patients had been considered commonly to be expiratory in quality. 1,3$), 4), 51,6)$ According to the above data, the work for breathing is closely related to dyspnea, and the non-elastic work in inspiration is same as or higher than that in expiration. Moreover, in inspiration the work for breathing is added with the work for elastic resistance, and in expiration the non-elastic work is partially performed by potential energy stored in the lung inspiratorily. For these reasons the typical dyspnea at least provocated by pilocarpin inhalation may be said to be inspiratory dyspnea rather than expiratory one. These experimental results seem to give an affirmative answer to clinical observations that asthmatic patients usually complain of inspiratory dyspnea.

It would seem to be of fundamental importance for genesis of bronchial asthma to determine separately the resistance due to air flow in bronchial canalization and the frictional resistance in the pulmonary tissue. The pressure difference between the intraalveolar pressure obtained with Vuilleumier's method and the pulmonary pressure measured by intraoesophageal balloon may occur theoretically due to the frictional resistance in the lung tissue. The experimental results of normal subjects reveal no difference between them and are consistent with the reports of Fry et al..$^{18)}$ and Mead et al. ${ }^{20)}$ (Fig. 8). On the other hand, there were some varieties in results obtained from asthmatic patients at attack, demon- 


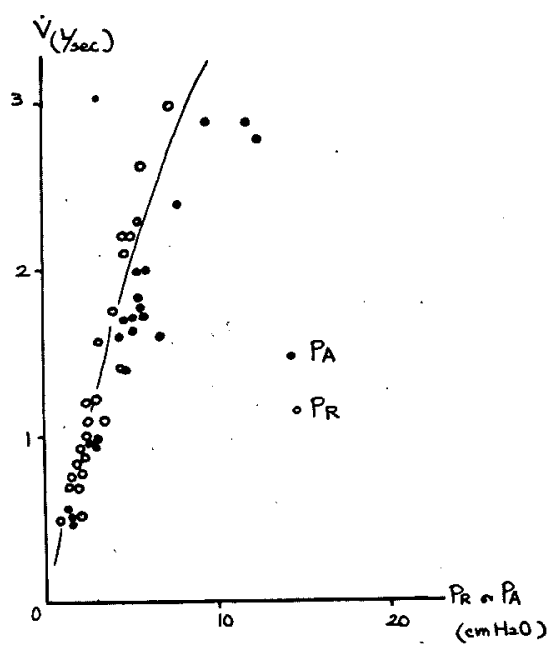

Fig. 8. Relationship between intraalveolar pressure and pulmonary pressure in each flow rate in a normal subject.

$\mathbf{P}_{\mathbf{A}}$ : intraalveolar pressure.

stratingโsome cases with definite differences and some case without any difference (Fig. 9). However, it is difficult to measure both the intraalveolar and pulmonary pressure during asthmatic attack mainly due to prolonged Iequilibration of pressures after interruption of air flow by the

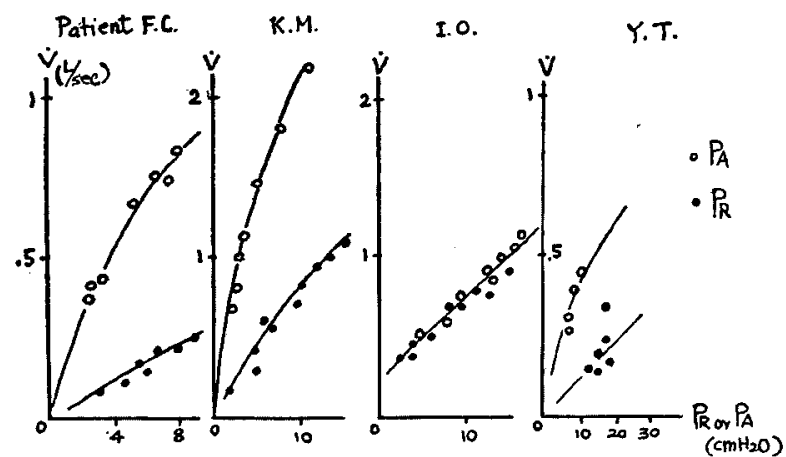

Fig. 9. Relationship between intraalveolar pressure and pulmonary pressure in each flow rate in 4 asthmatic patients during attacks.

interruption technique. In addition, Mead et al..$^{20)}$ reported that the intraalveolar pressure obtained with Vuilleumier's method may also include the pressure difference due to frictional tissue resistance. For these reasons, it is not necessarily implied but seems to be likely that the patients F. C., K. M. \& Y. T. have remarkably increased frictional resistances of the 
pulmonary tissues which are more intense than that of the flow resistance in bronchial canalization.

The diminution of the effective compliance in affected lung may be caused chiefly by following ${ }^{21,24)}$ :

I) the lung becomes stiff due to pulmonary congestion,

II) the alveoli with non-effective compliance increase due to uneven distribution of time constant in the lungs. If there are some uneven distributions of time constant in the lungs, the more frequent the breathing the smaller becomes the effective compliance. In high frequency of breathing, asthmatic patients in attack did not show any marked decrease of the effective compliance, as seen in Fig. 10. This result and the increase of frictional resistance in pulmonary tissue would seem to confirm occurance of the pulmonary congestion. However, present studies could not separate clearly these two resistances.

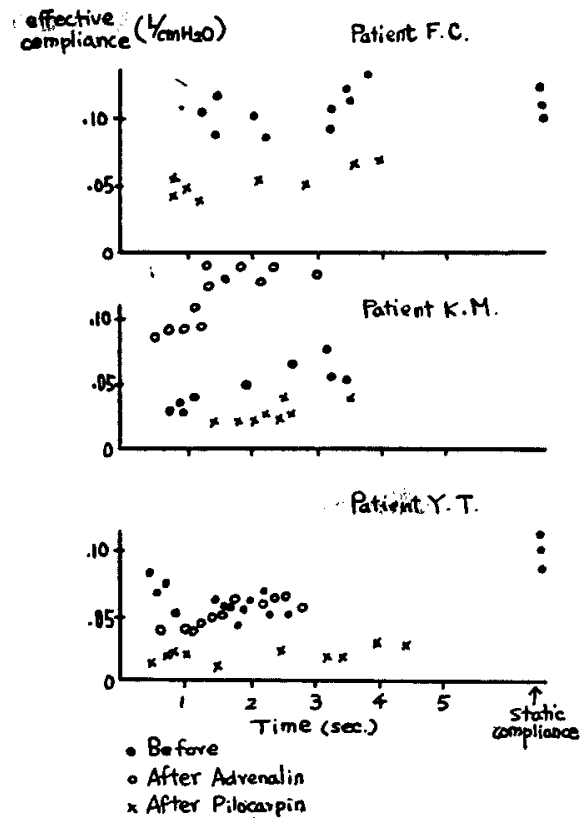

Fig. 10. Changes of the effective compliance due to changes of breathing frequency in 3 asthmatic patients. Time : time required for a single breathing cycle.

\section{ConCLUSION}

1. In 8 asthmatic patients, mechanical behaviors of the lung were studied during both remissions and asthmatic attack provocated with $1: 100$ pilocarpin inhalation. 
2. In remissions, the effective compliances of the lung in patients decrease, the maximal resistances increase considerably, and the nonelastic work is 4 -fold of that in normal subjects. The mean power factor is 0.75 compared to 0.45 in the normal.

3. After the attack was induced with 1:100 pilocarpin inhalation, VC, Tiffeneau's index and the effective compliance of the lung decreased, and the elastic work, the maximal resistance and the work for effective resistance increased distinctly except a patient without any dyspnea.

4. In attack, no check valve mechanism was observed at the beginning of expiration.

5. The objective dyspnea was closely related to the work required for total flow resistance as well as to the intrathoratic pressure fluctuation in a single breathing cycle. torily.

6. The dyspnea was much more severe inspiratorily than expira-

7. In some patients, the frictional resistance of the lung tissue increased presumably more than flow resitance in the bronchial canalization. This result seems to be explained by supposing that the pulmonary congestion occurs more intensely than the bronchial spasm does, resulting in decreased effective compliance of the lung and high frictional resistance in lung tissue.

\section{References}

1) Altschule, Physiology in diseases of the heart and lungs, Harvard University Press, Cambridge, 1948.

2) Comroe, The lung, The Year Book Publishers, Chicago.

3) Sheldon \& Otis, J. Appl. Physiol., 1951, 3, 513.

4) Sakamoto, Hagiwara \& Isikawa, Shinryo (Jap.), 1953, 6, 19.

5) Tsuji, Wesen und Behandlung des Bronchialasthma, Urban \& Schwarzenberg, 1939.

6) Gottlieb, Ann. Allergy, 1955, 13, 423.

7) Tiffeneau \& Drutel, Poumon, 1955, 11, 385.

8) Cara, C. R. de la Soc. et Biol., 1953, 147, 1233.

9) Brown, Fry \& Ebert, Am. J. Med., 1954, 17, 438.

10) Bayliss \& Robertson, Quart. J. Exp. Physiol., 1939, $29,27$.

11) Cara, Poumon, 1955, 11, 969.

12) Christie, Proc. Roy. Soc. Med., 1953, 46, 381.

13) Dayman, J. Clin. Invest., 1951, 30, 1175.

14) Dean, Am. J. Physiol., 1941, 134, 450.

15) Dornhorst \& Kelly, Lancet, 1954, No. 6806, 290.

16) Fenn, Am. J. Med., 1951, 10, 77.

17) Fry, Stead, Ebert, Lubin \& Wells, J. Lab. Clin. Med., 1952, 40, 664.

18) Fry, Ebert, Stead \& Brown, Am. J. Med., 1954, 16, 80.

19) Mead \& Whittenberger, J. Appl. Physiol., 1953, 5, 779.

20) Mead \& Whittenberger, ibid., 1954, 6, 408.

21) Mead, Lindgren \& Gaensler, J. Clin. Invest., 1955, 34, 1005. 
22) Mead, McIlroy, Selverstone \& Kriete, J. Appl. Physiol., 1955, 7, 491.

23) Otis, Physiol. Rev., 1954, 34, 449.

24) Otis, Mckerrow, Bartlett, Mead, McIlroy, Selverstone \& Radford, J. Appl. Physiol., $1956,8,427$.

25) Stead, Fry \& Ebert, S. Lab. Clin. Med., 1952, 40, 674. 